\title{
Modulation of radiation-induced tumour necrosis factor- $\alpha$ and transforming growth factor $\beta 1$ expression in the lung tissue by Shengqi Fuzheng injection
}

\author{
XIAO-RONG DONG, JING-NA WANG, LI LIU, XUE CHEN, MING-SHI CHEN, \\ JUAN CHEN, JING-HUA REN, QIN LI and JUN HAN \\ Cancer Center, Union Hospital, Tongji Medical College, \\ Huazhong University of Science and Technology, Hubei 430022, P.R. China
}

Received January 25, 2010; Accepted April 19, 2010

DOI: 10.3892/mmr_00000306

\begin{abstract}
Radiation-induced lung injury (RILI) is one of the most common and severe side effects of thoracic radiotherapy. Therefore, novel therapeutic approaches to improve the effectiveness of RILI treatment are required. The present study was designed to determine the effectiveness of a traditional Chinese medicine regimen, Shenqi Fuzheng injection (SFI), in the treatment of RILI. SFI is composed of extracts from codonopsis pilosula and radix astragali. Here, we determined the protective effects of SFI on RILI with a single-dose irradiation (RT) of 12 Gy in C57BL/6 8-week-old mice. The mice were divided into four groups treated with i) phosphatebuffered saline (PBS; pH 7.4, $20 \mathrm{ml} / \mathrm{kg} /$ day) alone as normal a control; ii) SFI only (20 ml/kg/day); iii) RT + PBS (20 ml/ $\mathrm{kg} /$ day); and iv) RT + SFI (20 ml/kg/day). SFI and PBS were administered via intraperitoneal injection 1 week before and 2 weeks after RT. The pathology of RILI and any clinical signs of toxicity were monitored. The expression of tumour necrosis factor (TNF)- $\alpha$ and transforming growth factor (TGF)- $\beta 1$ in the lungs was analyzed by RT-PCR and immunohistochemistry. TNF- $\alpha$ and TGF- $\beta 1$ expression was increased by RT, but was reversed by SFI treatment during the radiation pneumonic and fibrotic phases $(\mathrm{P}<0.05)$. Lung histology at 24 weeks revealed a significant decrease in structural damage and collagen deposition in the RT + SFI group compared to the RT + PBS group. In conclusion, TNF- $\alpha$ and TGF- $\beta 1$ are key mediators for the pathogenesis of RILI, and SFI reduces TNF- $\alpha$ and TGF- $\beta 1$ expression after RT. This may be a key mechanism behind the preventive effects of SFI on lung injury after radiation.
\end{abstract}

Correspondence to: Professor Li Liu, Cancer Center, Union Hospital, Tongji Medical College, Huazhong University of Science and Technology, Wujiadun 156, Jianghan, Wuhan, Hubei 430022, P.R. China

E-mail: hustliulixiehe2007@gmail.com

Key words: tumour necrosis factor- $\alpha$, transforming growth factor- $\beta 1$, Shenqi Fuzheng injection, radiation-induced lung injury

\section{Introduction}

Pulmonary radiation is an important curative and palliative modality in the treatment of thoracic cancer, but is often associated with toxicity to neighbouring normal tissues, which limits the deliverable dose intensity (1). The radiosensitivity of lungs represents a critical late toxicity issue after radiation therapy; clinical manifestations of lung toxicity, termed radiation-induced lung injury (RILI), mainly include radiation pneumonitis and lung fibrosis. RILI is the most common and most severe side effect of thoracic radiotherapy (2-4). It is usually unavoidable, seriously affects the quality of life of patients, and suggests a poor prognosis (5). The incidence of RILI is $10-20 \%$ (6); $50-100 \%$ of patients with RILI develop radiological evidence of regional lung injury, while 50-90\% experience a decline in pulmonary function (7). Early RILI manifests as radiation pneumonitis, occurs between 1 and 3 months of radiation, and is characterized by the loss of type I pneumocytes, increases in capillary permeability, interstitial edema, alveolar capillary congestion and the accumulation of inflammatory and immune cells from peripheral blood in the alveolar space. Radiation pneumonitis may trigger multiple repair mechanisms to restore lung function and remodel lung fibrosis (8-10). The duration (hours to days) before the obvious appearance of radiation pneumonitis is referred to as the 'latent' period, since no clear histopathologic signs are observed. If radiation pneumonitis develops, it leads to pulmonary fibrosis characterized by the loss of capillaries, thickened alveolar septa and obliteration of the alveolar space. The clinical symptoms of RILI are characterized by cough, dyspnea and fever.

Several studies have shown that pro-inflammatory cytokines play direct and indirect roles in the development of RILI (11-13). Tumour necrosis factor (TNF)- $\alpha$ and transforming growth factor (TGF)- $\beta 1$ are among the most crucial pro-fibrosis cytokines. TNF- $\alpha$ and TGF- $\beta 1$ expression is elevated in lung tissue after irradiation $(12,14,15)$. Therefore, in this study, TNF- $\alpha$ and TGF- $\beta 1$ were used as biomarkers to evaluate the effects of RILI treatment.

Although several agents have been used for the treatment of RILI (including glucocorticoid, angiotensin-1-converting 
enzyme inhibitors, non-steroidal anti-inflammatory drugs, adrenocorticotropic hormone and cortisone) (16), they show limited effectiveness and their adverse effects are significant, which limits their clinical application (17). A novel therapy for RILI with high efficacy and low toxicity is required. We have been interested in developing a Chinese traditional herbal medicine as a novel RILI therapy. The present study was designed to evaluate the effectiveness of a Chinese traditional medicine regimen, called Shenqi Fuzheng injection (SFI), in the treatment of RILI. SFI is composed of extracts from the traditional Chinese medicinal herbs codonopsis pilosula and radix astragali. In patients with cancer, SFI reduces the side effects of chemotherapy (18) and improves immune function (19) and quality of life (18). In a previous study, we demonstrated the effects of SFI in the treatment of radiation pneumonitis and its influence on the levels of TNF- $\alpha$, and TGF- $\beta$ at various stages (pre-, mid- and post-radiation) of irradiation (RT) (20). The objective of this study was to determine whether the administration of SFI has a protective effect on RILI, and to investigate the possible mechanisms behind these effects.

\section{Materials and methods}

Animals. Female C57BL/6 (C57BL/6NCrl) 8-week-old mice were obtained from Tongji Medical College (Wuhan, P.R. China) and housed 4-6 per cage in laminar flow hoods in a pathogen-free environment $\left(22 \pm 2^{\circ} \mathrm{C}, 55 \pm 10 \%\right.$ humidity and 12-12 h/light-dark cycle) with free access to a standard laboratory diet and water. Mice were allowed to acclimatize for 1 week prior to the experiments. The animal use and care protocol was reviewed and approved by the Medical Sciences Animal Care and Use Committee of Huazhong Science and Technology University.

Shenqi Fuzheng injection preparation. Livzon Pharmaceutics Ltd. (Zhuhai, P.R. China) provided the medicinal herbs used to prepare the Shengqi Fuzheng injection (Z19990065). Two raw herbs, codonopsis pilosula (Campanulaceae) and radix astragali (Leguminosae) were employed at a ratio of 1:1. The two herbs (10 g of each) were autoclaved and subsequently mixed with deionised water for a final volume of $10 \mathrm{ml}$, then maintained overnight at room temperature. The extract was centrifuged for $10 \mathrm{~min}$ at $1,000 \mathrm{x} \mathrm{g}(2,500 \mathrm{rpm})$ and the supernatant removed and filtered using a $0.2-\mu \mathrm{m}$ filter, providing a stock solution extract of $0.08 \mathrm{~g} / \mathrm{ml}$. The injection was identified and authenticated by the National Institute of Science Communication and Information Resources (21). The SFI was then used for high performance liqid chromatography (HPLC) analysis.

Irradiation. The mice were randomly divided into four groups: i) phosphate-buffered saline ( $\mathrm{PBS} ; \mathrm{pH} 7.4,20 \mathrm{ml} / \mathrm{kg} /$ day) alone as normal controls; ii) SFI only (20 ml/kg/day); iii) RT + PBS (20 ml/kg/day); and iv) RT + SFI (20 ml/kg/day). SFI and PBS were administered via intraperitoneal (i.p.) injection 1 week before irradiation. The mice were anesthetized with i.p. ketamine $(67.5 \mathrm{mg} / \mathrm{kg})$ and xylazine $(4.5 \mathrm{mg} / \mathrm{kg})$ and then irradiated. A single dose of 12 Gy was delivered to the lungs in a single fraction via a posterior field with a linear accelerator.
The dose distribution of the thoracic irradiation was evaluated by the ADAC Pinnacle three-dimensional treatment planning system. A plastic jig was used to restrain the mice and lead strips were placed to shield the head and abdomen (14). The irradiation protocol was: beam energy, $15 \mathrm{MV}$ photons; dose rate, $2.0 \mathrm{~Gy} / \mathrm{min}$; source-surface distance $(\mathrm{SSD}), 100 \mathrm{~cm}$; size of radiation field, $18 \times 10 \mathrm{~cm}$. The sham-irradiation areas (other than lung area) were shielded using lead blocks. Postirradiation, $20 \mathrm{ml} / \mathrm{kg} /$ day of SFI or PBS were administered for 14 days. Sham-irradiated control animals were maintained under identical conditions for the course of the experiment.

Tissue isolation. After anaesthesia by i.p. injection, the lung tissues of 3 mice were harvested at 1,24 and $72 \mathrm{~h}$, and at 2, 4, 8, 16 and 24 weeks post-irradiation. The right lung lobes were snap frozen in liquid nitrogen for RNA isolation and subsequent reverse transcriptase-polymerase chain reaction (RT-PCR) analysis. The left lobes were stored in $4 \%$ buffered formaldehyde for immunohistochemical (IHC) analysis.

Histology and immunohistochemistry. For histological analysis, the lung tissues were fixed in $4.5 \%$ neutral buffered formalin, paraffin-embedded and sectioned at an average thickness of $4 \mu \mathrm{m}$. Midsagittal sections of the lung lobes encompassing the largest surface area were collected for analysis. The mounted sections were stained by $H \& E$ or immunohistochemistry. For H\&E staining, the sections of left lung tissues were fixed in $10 \%$ neutral formaldehyde for $24 \mathrm{~h}$, dewaxed and rehydrated with xylene and alcohol. $\mathrm{H} \& \mathrm{E}$ staining was performed and semi-quantitative analysis methods were used to analyze the degree of alveolitis according to the method of Szapiel et al (22).

For TGF- $\beta 1$ and TNF- $\alpha$ IHC staining, the formalin-fixed and paraffin-embedded tissue sections were dewaxed in xylene and rehydrated in graded alcohol. Antigen retrieval was performed by heating the sections for $60 \mathrm{~min}$ with citrate buffer at $96^{\circ} \mathrm{C}$, then endogenous peroxidase activity was blocked with $3 \%$ hydrogen peroxide. After blocking the sections with normal rabbit serum, rabbit-anti-mouse primary anti-TGF- $\beta 1$ (R\&D system, Minneapolis, MN, USA) and TNF- $\alpha$ antibody (Abcam Inc, Cambridge, MA, USA) diluted 1:100 in PBS were applied to each section. The sections were incubated at $4^{\circ} \mathrm{C}$ in the humidified chamber overnight with biotinylated anti-rabbit antibody (Invitrogen, USA) diluted 1:200 in PBS for $1 \mathrm{~h}$, and then with avidin-biotin-peroxidase complex (ABC complex; Dako, Glostrup, Denmark) for $30 \mathrm{~min}$ at room temperature. After being washed with PBS, the sections were incubated with diaminobenzidine (DAB; Sigma) until a brown colour was visible, then placed in PBS to stop the reaction. Finally, the sections were counterstained with hematoxylin for $45 \mathrm{sec}$, dehydrated with ascending alcohol concentrations and mounted in Entellan (Merck, Darmstadt, Germany).

The results of immunohistochemistry were evaluated using a semi-quantitative scoring method (23). The slides were prepared for transmitted light microscopy (Olympus Provis microscope with a DP10 digital camera). TNF- $\alpha$ or TGF- $\beta 1$ staining was scored and subsequently calculated in 50 representative high power fields for each tissue sample. Cells with yellow/brown granules were regarded as positive. The 
A

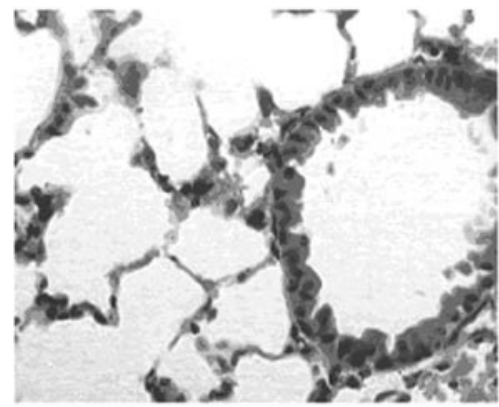

C

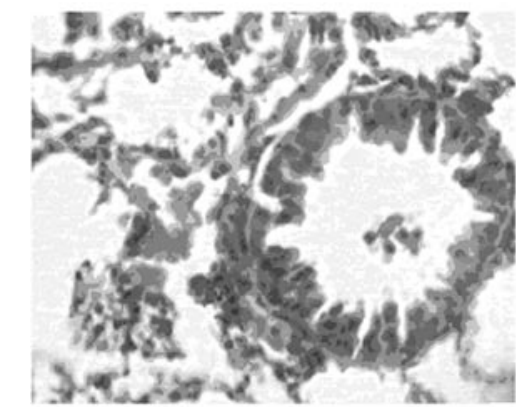

B

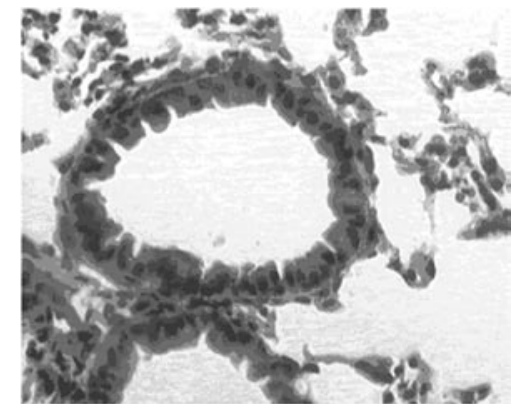

D

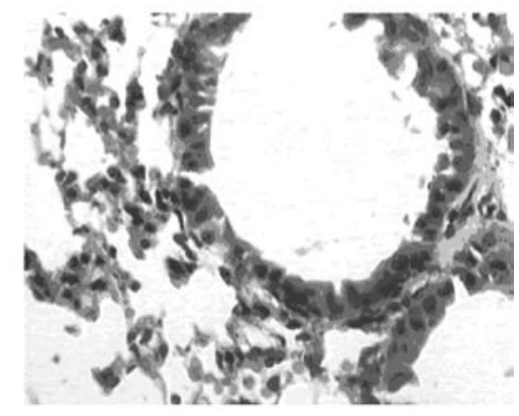

Figure 1. Qualitative histopathological analysis of radiation-induced lung injury in C57BL/6 mice. H\&E staining of the PBS and SFI groups showed no clear alveolitis (A and B). H\&E staining of the RT + PBS and RT + SFI groups showed overt alveolitis characterized by edema of the alveolar wall, hyperemia, widened alveolar septa and inflammatory cell infiltration at 4 weeks (C and D). Original magnification x400.

score according to the degree of positive staining in the lung tissue was defined as follows: 0 , no immunostaining; 1 , weak (light yellow); 2, moderate (yellow-brown); 3, strong (brown). The score according to the proportion of positive cells in the tissue was defined as follows: 0 , negative; $1,<10 \% ; 2,11-50 \%$; $3,51-75 \% ; 4,>75 \%$. After calculating the product of the two immunohistochemical scores, a score of $>3$ was defined as a positive immune response.

RT-PCR analysis. Frozen samples of pulmonary tissue $(75 \mathrm{mg}$ ) were homogenized in $1 \mathrm{ml}$ of TRIzol reagent (Gibco BRL, Life Technologies, USA). Total RNA preparation was performed according to the manufacturer's instructions. Tissue lysates were stored at $-85^{\circ} \mathrm{C}$ before processing or were used directly in the procedure according to the manufacturer's protocol. Ribonucleic acid concentrations were determined by spectrophotometric absorption at $260 \mathrm{~nm}$. One-step RT-PCR was performed according to the manufacturer's instructions (Promega). Total RNA $(4 \mu \mathrm{l})$ was used as a template to synthesize cDNA in a $25-\mathrm{ml}$ reaction mixture containing $2.5 \mathrm{mM}$ oligo d(T)16 primers and M-MLV Reverse Transcriptase (Promega) at $37^{\circ} \mathrm{C}$ for $1 \mathrm{~h}$, followed by $95^{\circ} \mathrm{C}$ for $4 \mathrm{~min}$. The PCR was performed with a $20-\mathrm{ml}$ reaction mixture $(5 \mu \mathrm{l} 10 \mathrm{X}$ buffer, $2 \mu \mathrm{l}$ template cDNA, $4 \mu \mathrm{l}$ of each dNTPs, $5 \mu \mathrm{MgCl}_{2}$, $1 \mu \mathrm{l}$ of each primer and $0.5 \mu \mathrm{l}$ Taq polymerase), to which $\mathrm{ddH}_{2} \mathrm{O}$ was added for a final volume of $50 \mu \mathrm{l}$. The conditions were as follows: $94^{\circ} \mathrm{C}$ for $4 \mathrm{~min}$, followed by 30 cycles at $94^{\circ} \mathrm{C}$ for $30 \mathrm{sec}, 57^{\circ} \mathrm{C}$ for $40 \mathrm{sec}, 72^{\circ} \mathrm{C}$ for $40 \mathrm{sec}$ and, finally, $72^{\circ} \mathrm{C}$ for $5 \mathrm{~min}$. The primer sequences for PCR amplification were as follows: TGF- $\beta 1$ sense (5'-GGA GCA ACA TGT GGA ACT CTA CC-3') and anti-sense (5'-GAC GTC AAA AGA CAG CCA CTC AG-3'); TNF- $\alpha$ sense (5'-AGG CGG TGC CTA TGT CTC A-3') and anti-sense (5'-GAG GCC ATT TGG GAA CTT CT-3'). As an internal control, a GAPDH cDNA fragment was simultaneously amplified using sense (5'-TCA CCA CCA TGG AGA AGG C-3') and anti-sense (5'-GCT AAG CAG TTG GTG GTG CA-3') primers. The above primers were synthesized by Dalian Baosheng Bioengineering Co (Dalian, P.R. China). PCR product sizes were 109 bp (TGF- $\beta 1$ ), 123 bp (TNF- $\alpha$ ) and 168 bp (GAPDH), respectively. The PCR products were visualized by electrophoresis of $7 \mu \mathrm{l}$ of reaction mixture on a $1 \%$ agarose gel containing $0.5 \mathrm{mg} / \mathrm{ml}$ ethidium bromide (EB; Sigma) at $70 \mathrm{~V}$ for $40 \mathrm{~min}$, and quantitated by densitometry using a dual-intensity transilluminator equipped with Gel-Pro Analyzer version 3.1. $\beta$-actin was used as an internal control. The R-value of mRNA expression was evaluated by the band-intensity ratio of TNF- $\alpha$ or TGF- $\beta 1$ to GDPDH.

Statistical analysis. Data analysis was performed using SPSS13.0 statistical software with one-way analysis of variance (ANOVA) followed by Bonferroni correction. A P-value of $\leq 0.05$ was considered to be significant.

\section{Results}

Histological changes. Qualitative and quantitative analyses of the histopathologic alterations of RILI in C57BL/6 mice were performed, and the results were in agreement with those described previously (24). H\&E staining showed no obvious alveolitis in the PBS and SFI groups, but overt alveolitis was found in the RT + PBS and RT + SFI groups, characterized by edema of the alveolar wall, hyperemia, widened alveolar septa and by inflammatory cell infiltration at various time points, from $1 \mathrm{~h}$ to 4 weeks (Fig. 1). The mean grade of alveolitis was $0-1$ in the RT + SFI group, which is significantly lower (better) than that in the RT + PBS group (grade 2-3; $\mathrm{P}<0.05$ ), indicating the effectiveness of SFI in preventing RILI. 


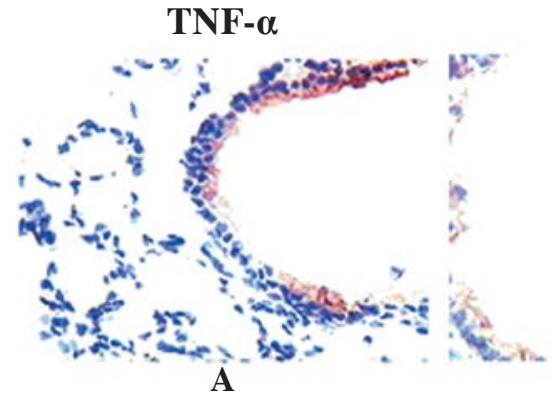

TGF-ß1
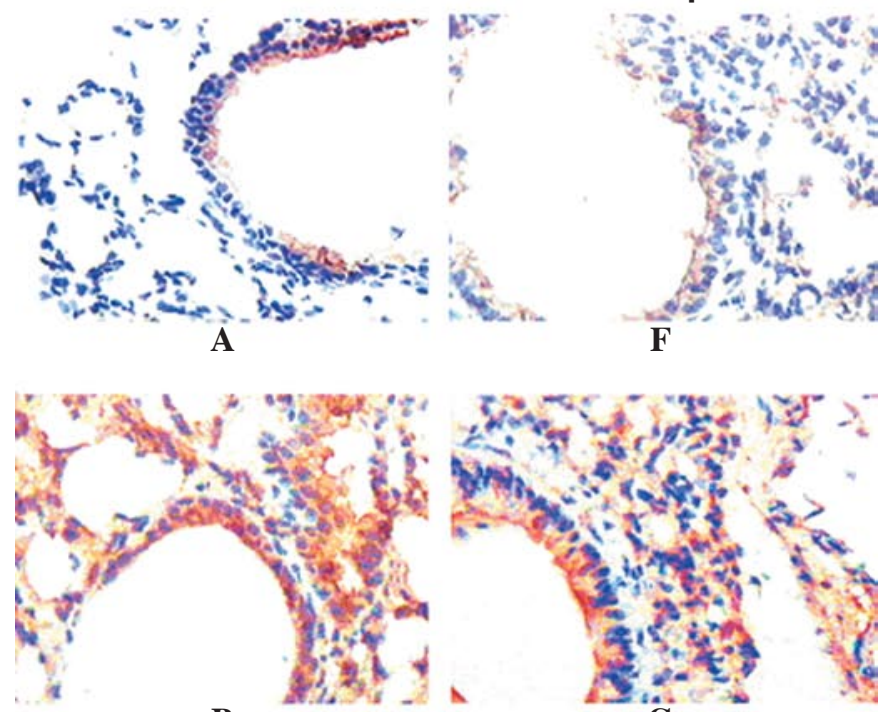

B
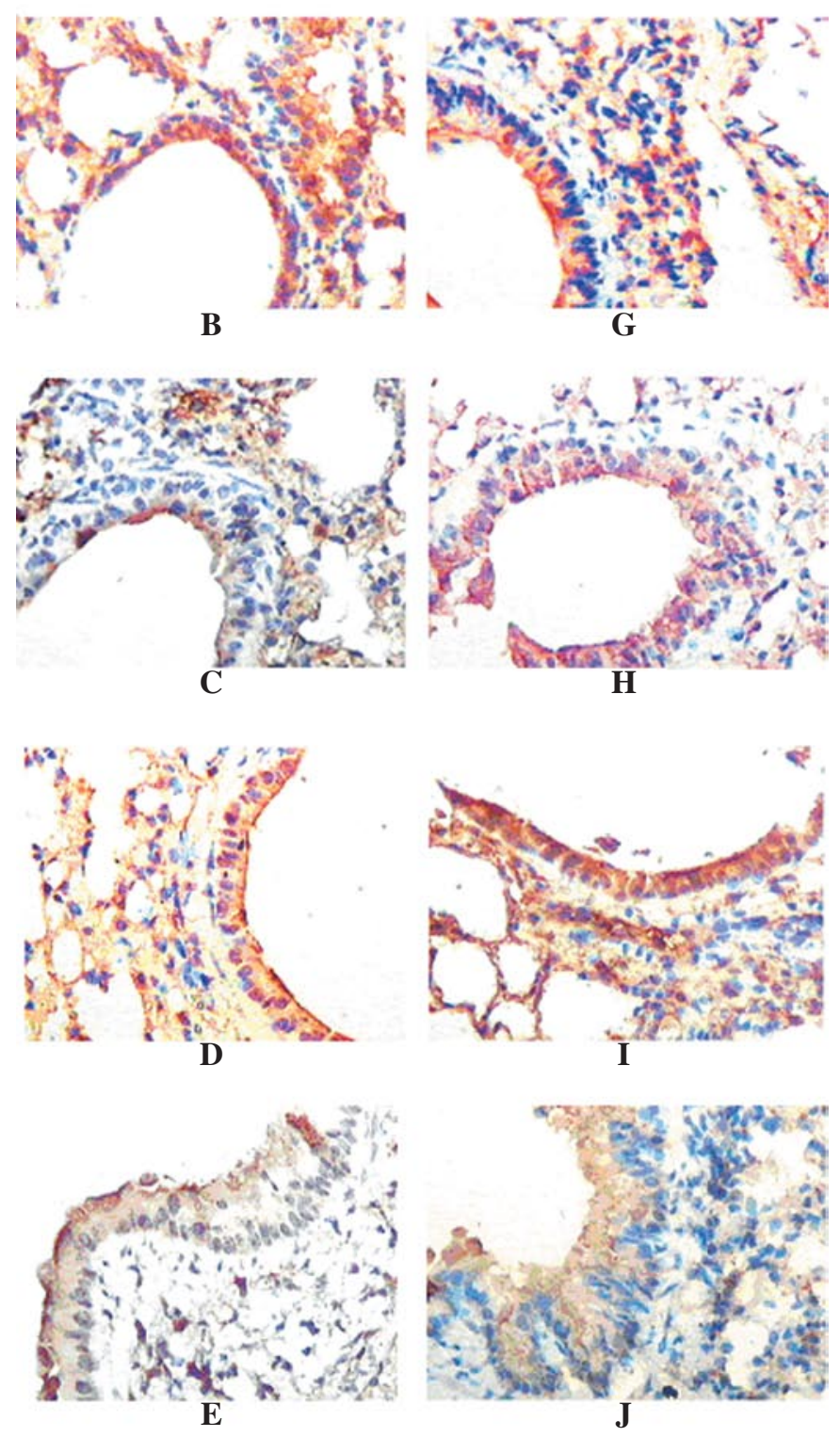

Figure 2. Immunohistochemical analysis of TNF- $\alpha$ and TGF- $\beta 1$ expression. In the PBS and SFI only groups, TNF- $\alpha$ (A) and TGF- $\beta 1$ (D) positive staining was restricted to the single cells of the bronchiolar epithelium. Immunohistochemical staining of TNF- $\alpha$ (B) and TGF- $\beta 1(\mathrm{G})$ in lung tissue obtained 4 weeks after 12 Gy thoracic irradiation in the RT + PBS group, which showed strong immunostaining of the bronchional epithelium and of interstitial inflammatory cells. Immunohistochemical staining of TNF- $\alpha$ (C) and TGF- $\beta 1(\mathrm{H})$ in lung tissue obtained 8 weeks after 12 Gy thoracic irradiation in the RT + PBS group, which showed strong immunostaining of the bronchional epithelium and of interstitial inflammatory cells. Samples collected at 4 and 8 weeks after 12 Gy RT with SFI showed decreased expression of TNF- $\alpha$ (D) and TGF- $\beta 1$ (I) in the bronchional epithelium and fewer interstitial inflammatory cells. Samples collected at 4 and 8 weeks after 12 Gy RT with SFI showed decreased expression of TNF- $\alpha$ (F) and TGF- $\beta 1$ (J) in the bronchional epithelium and fewer interstitial inflammatory cells. Original magnification, $\mathrm{x} 400$.
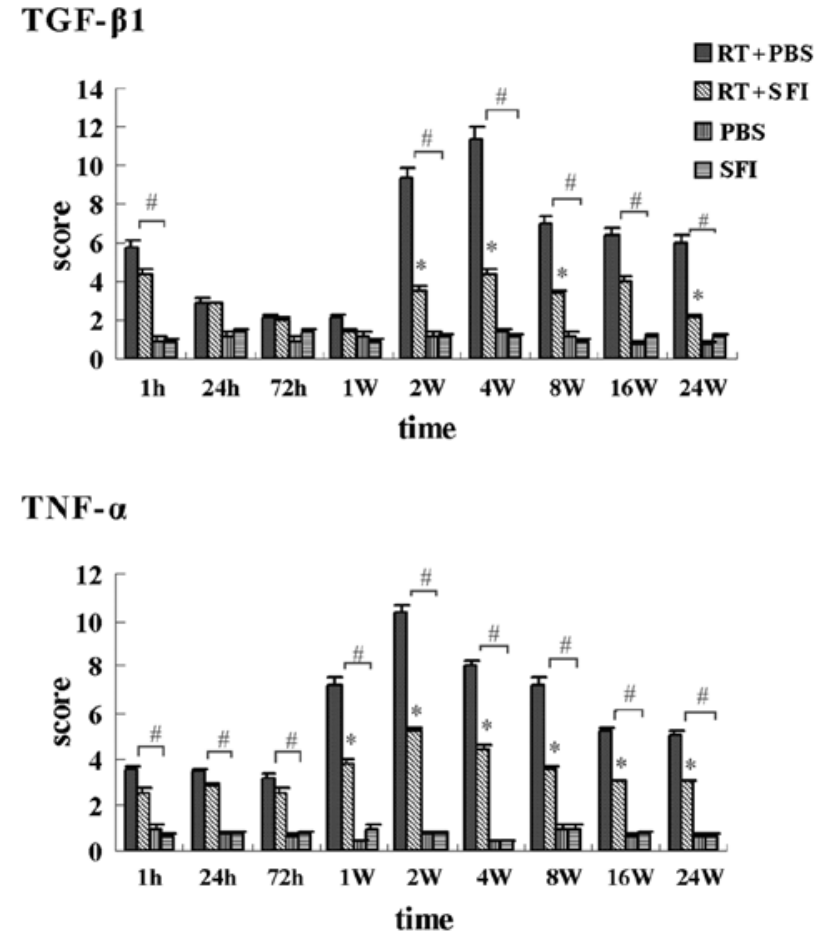

Figure 3. Immunohistochemistry score of TNF- $\alpha$ and TGF- $\beta 1$ in the groups. Data are the mean \pm SD of triplicate determinations using three mice. *Statistically significant differences between the RT + PBS and RT + SFI groups. "Statistically significant differences between the RT and sham-RT groups.

Immunohistochemical analysis of TNF- $\alpha$ and TGF- $\beta 1$. There were no significant changes in the expression of TNF- $\alpha$ and TGF- $\beta 1$ at any time point in the PBS and SFI groups $(\mathrm{P}>0.05)$. As shown in Fig. 2 , significant increases in TGF- $\beta 1$ and TNF- $\alpha$ expression were observed at every time point post-irradiation for all the RT groups compared to the PBS and SFI groups by IHC analysis. IHC staining of TNF- $\alpha$ and TGF- $\beta 1$ in the lung tissue of the PBS and SFI groups showed that positive staining was restricted to single cells of the bronchiolar epithelium, while TNF- $\alpha$ and TGF- $\beta 1$ staining obtained 4 weeks after irradiation showed strong immunostaining of the bronchial epithelium and of interstitial inflammatory cells. Treatment with SFI attenuated the expression of TNF- $\alpha$ and TGF- $\beta 1$ in lung tissue post-irradiation. The immunohistochemical scores of TGF- $\beta 1$ and TNF- $\alpha$ varied with time (Fig. 3). The TNF- $\alpha$ immunohistochemical score peaked at 2 weeks post-irradiation, while the TGF- $\beta 1$ score peaked at 4 weeks post-irradiation. Although the changes in TGF- $\beta 1$ and TNF- $\alpha$ expression followed the same trend in both the RT + SFI and RT + PBS groups, the former had significantly lower levels of expression than the latter for all time points 1 week (TNF- $\alpha$ ) or 2 weeks (TGF- $\beta 1$ ) after irradiation (Fig. 3, $\mathrm{P}<0.05$ ). This indicates that SFI had a significant impact on the production of pro-inflammatory cytokines after radiation therapy.

TNF- $\alpha$ and TGF- $\beta 1$ expression based on RT-PCR analysis. As observed with IHC analysis, there were no significant changes in the mRNA levels of TNF- $\alpha$ or TGF- $\beta 1$ in the PBS and SFI groups at any time point (Fig. 4, P>0.05). The mRNA expression of TNF- $\alpha$ and TGF- $\beta 1$ was increased at $1 \mathrm{~h}$ post- 


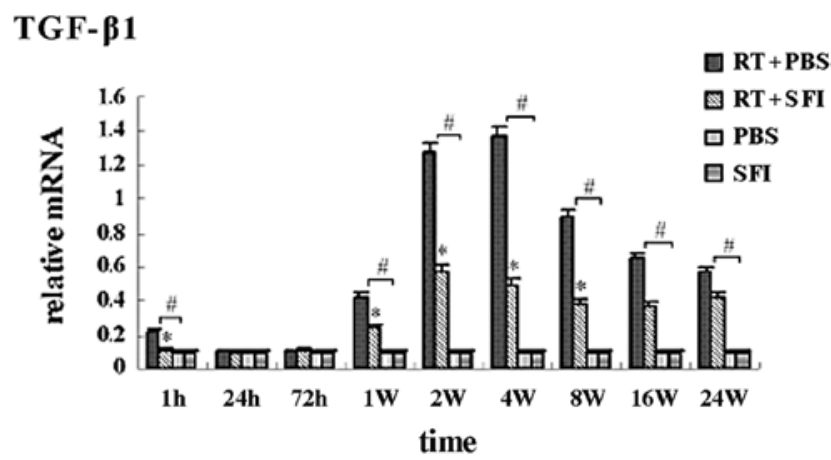

TNF- $\alpha$

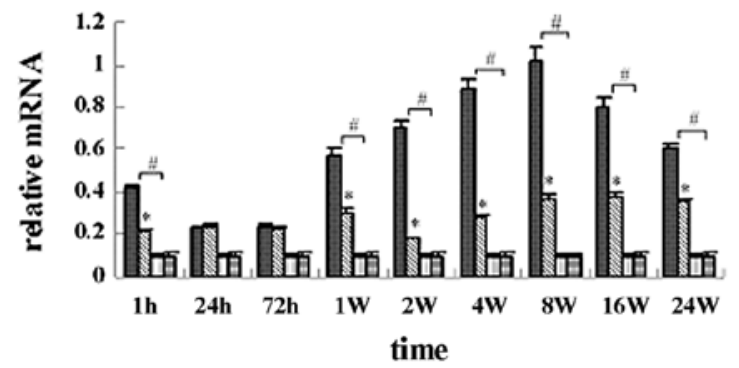

Figure 4. TNF- $\alpha$ and TGF- $\beta 1$ mRNA expression in the groups. Data are the mean \pm SD of triplicate determinations using three mice. "Statistically significant differences between the RT + PBS and RT + SFI groups. "Statistically significant differences between the RT and sham-RT groups.

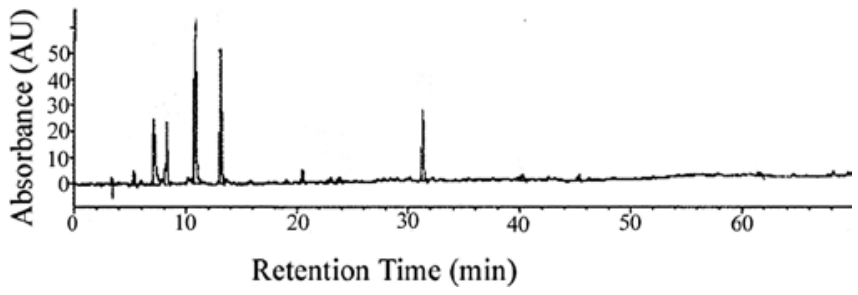

Figure 5. High performance liqid chromatography fingerprinting of Shengqi Fuzheng injection.

irradiation, but was decreased during the latent period of RILI, achieving the same level as the control groups (Fig. 4, $\mathrm{P}>0.05)$. The expression of both genes increased significantly during the period of radiation pneumonitis, reaching a peak during the pulmonary fibrosis phase. As illustrated in Fig. 4, significant increases in TGF- $\beta 1$ and TNF- $\alpha$ mRNA expression were found in all the RT groups compared to the control groups at all time points post-irradiation, except for 24 and $72 \mathrm{~h}(\mathrm{P}<0.05)$. The mRNA levels of both genes in the RT + SFI group were significantly lower than those in the RT + PBS mice (Fig. 4, all $\mathrm{P}<0.05$ ) except for two time points, 24 and $72 \mathrm{~h}$ ( $\mathrm{P}>0.05)$. TNF- $\alpha$ mRNA expression peaked at 8 weeks after irradiation, while TGF- $\beta 1$ mRNA expression reached its peak at 4 weeks after irradiation.

HPLC fingerprinting of Shengqi Fuzheng injection. Using HPLC fingerprint analysis, codonopsis pilosula and radix astragali were determined to be the only two ingredients in the injection (Fig. 5).

\section{Discussion}

Lung cancer is a major health problem worldwide and has the highest morbidity and mortality rate among all types of cancer in China (25). The efficacy of current therapeutic approaches such as surgery is often limited. Since many lung cancer patients are frequently diagnosed at an advanced stage, approximately $30 \%$ of patients are not candidates for surgery. Thus, chemo- or radiotherapy is the main treatment option (26). Radiotherapy plays a major role in lung cancer treatment, with $53.6 \%$ of small cell lung cancer and $64.3 \%$ of non-small cell lung cancer patients in different stages of the disease receiving radiotherapy. Approximately $46 \%$ of patients undergo radiotherapy as the first treatment (27). However, side effects, including RILI, limit the success of the treatment. At present, there is a trend emphasizing the quality of life in cancer patients receiving radiotherapy in addition to its cancer-killing effects. RILI arises from the injury of normal lung tissues, limiting the effectiveness, dose and schedule of radiotherapy and reducing the quality of life of patients. Adrenocorticotropic hormone and cortisone are the main drugs for RILI (16), but their effectiveness is poor and their adverse effects are significant. Thus, the prevention of RILI with novel drugs represents a new avenue for dealing with these side effects of radiation therapy.

Several clinical factors are associated with lung toxicity, including tumor location (28-30), patient performance status $(31,32)$, pulmonary function before radiotherapy (32) and smoking status $(31,33)$. In addition, many studies have demonstrated that dosimetric factors are crucial for the estimation of lung tolerance, including mean lung dose, the percentage of the total lung volume exceeding 20 Gy (V20), the percentage of the total lung volume exceeding $30 \mathrm{~Gy}$ (V30), effective volume and normal tissue complication probability from the lung dose-volume histogram (34-37). However, the accuracy of these parameters is limited (38).

RILI frequently involves several cell types within lung tissue, including type II pneumocytes, endothelial cells, macrophages and phoroblasts (39). It has been demonstrated that type II pneumocytes and endothelial cells release proinflammatory cytokines such as IL-1, IL-6 and TNF- $\alpha$, which could activate macrophages, leading to the production of pro-fibrosis cytokines such as PDGF and TGF- $\beta$ and inducing the hyperplasia of phoroblasts and the synthesis of cell matrix proteins by a series of autocrine or paracrine secretions. Cytokines such as TGF- $\beta 1$ and TNF- $\alpha$ initiate and sustain the inflammatory and fibrogenic processes associated with RILI $(12,14,15,24,40)$. Several studies suggest that TGF- $\beta$ has an important role at the beginning and end of the pathologic changes during chronic fibrosing processes $(41,42)$. TGF- $\beta 1$ also plays an important role in repairing tissue injury and is one of the most critical cytokines in the formation of fibrosis (43). The rise of TGF- $\beta 1$ levels in plasma and bronchoalveolar lavage fluid directly reflects the severity of RILI (44-48), and TGF- $\beta 1$ has been suggested as a sensitive plasma marker of RILI post-irradiation (47). The importance of TNF- $\alpha$ in the development and progression of RILI has also been suggested. TNF- $\alpha$ as a cytokine network regulator plays a key role in initiating local inflammatory responses, and then further attracts and activates macrophages, lymphocytes and stromal 
cells, indirectly enhancing the generation of pro-inflammatory cytokines. TNF- $\alpha$ also modulates fibroblast proliferation and differentiation and ECM protein synthesis in the subsequent fibrotic phase. Therefore, regulating TNF- $\alpha$ and TGF- $\beta 1$ expression may provide a novel approach to the prevention and treatment of RILI.

In the present study, we demonstrated the therapeutic effects of the Shenqi Fuzheng injection, a traditional Chinese medicine preparation, on RILI in experimental mice. Previous studies have shown that the effectiveness of the combination of SFI and glucocorticoid is significantly higher than that of glucocorticoid alone, with the time to alleviate clinical symptoms being remarkably shorter (48). In our previous study $(20,49)$, SFI significantly decreased the fibrogenic expression of TNF- $\alpha$ and TGF- $\beta 1$ in patients after chest irradiation and maintained anti-fibrogenic cytokine IL-10 levels, decreasing the incidence of radiation pneumonitis. These results indicate that SFI can be used as an effective adjuvant drug in the treatment of radiation pneumonitis, based on its effects on the regulation of the cytokine network.

In the present study, we demonstrated that SFI treatment significantly attenuated lung injury assessed by histological, IHC and PCR analyses. Mice in the RT alone group exhibited radiation pneumonitis characterized by acute inflammation and edema, followed by increased collagen and fibrosis during the subsequent fibrotic phase post-irradiation. SFI treatment may attenuate RILI, as determined by H\&E staining after radiotherapy of the severity of alveolitis, IHC staining of mouse lung tissue TNF- $\alpha$ and TGF- $\beta 1$ protein expression, and RT-PCR detection of TNF- $\alpha$ and TGF- $\beta 1$ mRNA expression. The efficacy of treatment with SFI in RILI was found to be related to the enhanced suppression of radiation-induced TNF- $\alpha$ and TGF- $\beta 1$ expression. These results provide a basis for future clinical studies of SFI as a novel agent in the prevention and treatment of RILI in patients with lung cancer.

\section{Acknowledgements}

This work was supported by grants from the Clinical Oncology Foundation of China (20033452) and the Science and Technology Foundation of Hubei Province, P.R. China (2005AA401C5).

\section{References}

1. Ghafoori P, Marks LB, Vujaskovic Z and Kelsey CR: Radiationinduced lung injury. Assessment, management, and prevention. Oncology (Williston Park) 22: 37-47; 52-53, 2008.

2. Marks LB, Munley MT, Bentel GC, Zhou SM, Hollis D, Scarfone C and Sibley GS: Physical and biological predictors of changes in whole-lung function following thoracic irradiation. Int J Radiat Oncol Biol Phys 39: 563-570, 1997.

3. Kong FM, Hayman JA, Griffith KA, Kalemkerian GP, Arenberg D, Lyons S and Turrisi A: Final toxicity results of a radiation-dose escalation study in patients with non-small-cell lung cancer (NSCLC): predictors for radiation pneumonitis and fibrosis. Int J Radiat Oncol Biol Phys 65: 1075-1086, 2006.

4. Hope AJ, Lindsay PE, EINaqa I, Alaly JR, Vicic M, Bradley JD and Deasy JO: Modeling radiation pneumonitis risk with clinical, dosimetric, and spatial parameters. Int J Radiat Oncol Biol Phys 65: 112-124, 2006.

5. Ohe Y, Yamamoto S, Suzuki K, Hojo F, Kakinuma R, Matsumoto T and Ohmatsu H: Risk factors of treatment-related death in chemotherapy and thoracic radiotherapy for lung cancer. Eur J Cancer 37: 54-63, 2001.
6. Mehta V: Radiation pneumonitis and pulmonary fibrosis in non-small cell lung cancer: pulmonary function, prediction, and prevention. Int J Radiat Oncol Biol Phys 63: 5-24, 2005.

7. Fan M, Marks LB, Hollis D, Bentel GG, Anscher MS, Sibley G and Coleman RE: Can we predict radiation-induced changes in pulmonary function based on the sum of predicted regional dysfunction? J Clin Oncol 19: 543-550, 2001.

8. Borst GR, Jaeger K, Belderbos JS, Burgers SA and Lebesque JV: Pulmonary function changes after radiotherapy in non-smallcell lung cancer patients with long-term disease-free survival. Int J Radiat Oncol Biol Phys 62: 639-644, 2005.

9. Epperly MW, Franicola D, Zhang X, Nie S, Wang H, Bahnson AB and Shields DS: Reduced irradiation pulmonary fibrosis and stromal cell migration in Smad3-/- marrow chimeric mice. In Vivo 20: 573-582, 2006.

10. Schallenkamp JM, Miller RC, Brinkmann DH, Foote T and Garces YI: Incidence of radiation pneumonitis after thoracic irradiation: dose volume correlates. Int J Radiat Oncol Biol Phys 67: 410-416, 2007.

11. Franko AJ and Sharplin J: Assessment of radiation-induced lung injury in mice using carbon monoxide uptake: correlation with histologically visible damage. Radiat Res 133: 245-251, 1993.

12. Rübe CE, Uthe D, Wilfert F, Ludwig D, Yang K, König J and Palm J: The bronchiolar epithelium as a prominent source of pro-inflammatory cytokines after lung irradiation. Int J Radiat Oncol Biol Phys 61: 1482-1492, 2005.

13. Tsoutsou PG and Koukourakis MI: Radiation pneumonitis and fibrosis: mechanisms underlying its pathogenesis and implications for future research. Int J Radiat Oncol Biol Phys 66: 1281-1293, 2006.

14. Rübe CE, Wilfert F, Uthe D, Schmid KW, Knoop R, Willich N and Schuck A: Modulation of radiation-induced tumour necrosis factor alpha (TNF-alpha) expression in the lung tissue by pentoxifylline. Radiother Oncol 64: 177-187, 2002.

15. Rübe CE, Wilfert F, Palm J, König J, Burdak-Rothkamm S, Liu L and Schuck A: Irradiation induces a biphasic expression of pro-inflammatory cytokines in the lung. Strahlenther Onkol 180: 442-448, 2004.

16. Sekine I, Sumi M, Ito Y, Nokihara H, Yamamoto N, Kunitoh $\mathrm{H}$ and Ohe Y: Retrospective analysis of steroid therapy for radiation-induced lung injury in lung cancer patients. Radiother Oncol 80: 93-97, 2006.

17. Kosaka Y, Mitsumori M, Araki N, Yamauchi C, Nagata Y, Hiraoka $\mathbf{M}$ and Kodama $\mathrm{H}$ : Avascular necrosis of bilateral femoral head as a result of long-term steroid administration for radiation pneumonitis after tangential irradiation of the breast. Int J Clin Oncol 11: 482-486, 2006.

18. Yu SZ, Yang GH and Feng JM: Clinical study on treatment of malignant neoplasms with Shenqi Fuzheng Injection and chemotherapy. J Chin Integr Med 4: 84-86, 2006.

19. Dai ZJ, Wang XJ, Kang HF, Ji ZZ, Liu L, Liu XX and Song LQ: Clinical effects of Shengqi Fuzheng Injection in the neoadjuvant chemotherapy for local advanced breast cancer and the effects on T-lymphocytes subsets. J Trad Chin Med 28: 34-38, 2008.

20. Liu L, Ding Q, Dai XF, Zhao YX, Ke Y and Wu G: Study on the controlling effect of Shengqi Fuzheng Injection on plasma cytokine network in patients with thoracic tumor undergoing radiotherapy. Chin J Integrated Trad Western Med 12: 1082-1085, 2007.

21. Sheng LS and Song Min: The component analysis of Shengqi injection. Chinese Prescribed Drug 29: 47-48, 2004.

22. Szapiel SV, Elson NA, Fulmer JD, Hunninghake GW and Crystal RG: Bleomycin-induced interstitial pulmonary disease in the nude, athymic mouse. Am Rev Respir Dis 12: 893-899, 1979.

23. Fricdrichs K, Gluba S, Eidtmann $\mathrm{H}$ and Jonat W: Overexpression of P53 and prognosis in breast cancer. Cancer 72: 3641-3647, 1993.

24. Rübe CE, Uthe D, Schmid KW, Richter KD, Wessel J, Schuck A and Willich N: Dose-dependent induction of transforming growth factor $\beta$ (TGF- $\beta$ ) in the lung tissue of fibrosis-prone mice after thoracic irradiation. Int J Radiat Oncol Biol Phys 47: 1033-1042, 2000.

25. Parkin DM, Bray F, Ferlay J and Pisani P: Global cancer statistics, 2002. CA Cancer J Clin 55: 74-108, 2005.

26. Bülzebruck H, Bopp R, Drings P, Bauer E, Krysa S, Probst G and van Kaick G: New aspects in the staging of lung cancer. Prospective validation of the international union against cancer TNM classification. Cancer 70: 1102-1110, 1992. 
27. Tyldesley S, Boyd C, Schulzem K, Walker H and Mackillop WJ: Estimating the need for radiotherapy for lung cancer: an evidence-based, epidemiologic approach. Int J Radiat Oncol Biol Phys 49: 973-985, 2001

28. Yamada M, Kudoh S, Hirata K, Nakajima T and Yoshikawa J: Risk factors of pneumonitis following chemoradiotherapy for lung cancer. Eur J Cancer 34: 71-75, 1998.

29. Khan MA, Yeung IWT, Van Dyk J, Yeung IW and Hill RP: Partial volumer at lung irradiation: assessment of early DNA damage in different lung regions and effect of radical scavengers. Radiother Oncol 66: 95-102, 2003.

30. Moiseenko VV, Battista JJ, Hill RP, Travis EL and van Dyk J: In-field and out-of-field effects in partial volume lung irradiation in rodents: possible correlation between early DNA damage and functional endpoints. Int J Radiat Oncol Biol Phys 48: 1539-1548, 2000.

31. Jin H, Tucker SL, Liu HH, Wei X, Yom SS, Wang S and Komaki R: Dose-volume thresholds and smoking status for the risk of treatment-related pneumonitis in inoperable non-small cell lung cancer treated with definitive radiotherapy. Radiother Oncol 91: 427-432, 2009.

32. Robnett TJ, Machtay M, Vines EF, Mckenna MG, Algazy KM and Mckenna WG: Factors predicting severe radiation pneumonitis in patients receiving definitive chemoradiation for lung cancer. Int J Radiat Oncol Biol Phys 48: 89-94, 2000.

33. Hernando ML, Marks LB, Bentel GC, Zhou SM, Hollis D, Das SK and Fan M: Radiation-induced pulmonary toxicity: a dose-volume histogram analysis in 201 patients with lung cancer. Int J Radiat Oncol Biol Phys 51: 650-659, 2001.

34. Yorke ED, Jackson A, Rosenzweig KE, Merrick SA, Gabrys D, Venkatraman ES and Burman CM: Dose-volume factor contributing to the incidence of radiation pneumonitis in non-small- cell lung cancer patients treated with three-dimensional conformal radiationtherapy. Int J Radiat Oncol Biol Phys 54: 329-339, 2002.

35. Rancati T, Ceresoli GL, Gagliardi G, Schipani S and Cattaneo GM: Factors predicting radiation pneumonitis in lung cancer patients: a retrospective study. Radiother Oncol 67: 275-283, 2003

36. Graham MV, Purdy JA, Emami B, Harms W, Bosch W, Lockett MA and Perez CA: Clinical dose volume histogram analysis for pneumonitis after 3D treatment for non-small cell lung cancer (NSCLC). Int J Radiat Oncol Biol Phys 45: 323-329, 1999.

37. Kwa SL, Lebesque JV, Theuws JC, Marks LB, Munley MT, Bentel G and Oetzel D: Radiation pneumonitis as a function of mean lung dose: ananalysis of pooled data of 540 patients. Int J Radiat Oncol Biol Phys 42: 1-9, 1998.
38. Rodrigues G, Lock M, D Souza D, Yu E and van Dyk J: Prediction of radiation pneumonitis by dose volume histogram parameters in lung cancer a systematic review. Radiother Oncol 71: $127-138,2004$

39. Herrmann T, Kasper M and Kasper M: Target cells in radiation pneumopathy. Int J Radiat Oncol Biol Phys 2: 463-469, 2004.

40. Zhao L, Sheldon K, Chen M, Yin MS, Hayman JA, Kalemkerian GP and Arenberg D: The predictive role of plasma TGF-beta1 during radiation therapy for radiation-induced lung toxicity deserves further study in patients with non-small cell lung cancer. Lung Cancer 59: 232-239, 2008.

41. Leask A and Abraham DJ: TGF-beta signaling and the fibrotic response. FASEB J 18: 816-827, 2004

42. Vujaskovic Z, Marks LB and Anscher MS: The physical parameters and molecular events associated with radiation-induced lung toxicity. Semin Radiat Oncol 10: 296-307, 2000.

43. Sanderson N, Factor V, Nagy P, Kopp J, Kondaiah P, Wakeeld L and Roberts AB: Hepatic expression of mature transforming growth factor betal in transgenic mice results in multiple tissue lesions. Proc Natl Acad Sci USA 92: 2572-2576, 1995.

44. Chen Y, Williams J, Ding I, Hernady E, Liu W, Smudzin T and Finkelstein JN: Radiation pneumonitis and early circulatory cytokine markers. Semin Radiat Oncol 12 (Suppl 1): 26-33, 2002.

45. Evans ES, Kocak Z, Zhou SM, Kahn DA, Huang H, Hollis DR and Light KL: Does transforming growth factor-1 predict for radiation-induced pneumonitis in patients treated for lung cancer? Cytokine 35: 186-192, 2006.

46. Fu XL, Huang H, Bentel G, Clough R, Jirtle RL, Kong FM and Marks LB: Predicting the risk of symptomatic radiation-induced lung injury using both the physical and biologic parameters $\mathrm{V}$ (30) and transforming growth factor beta. Int J Radiat Oncol Biol Phys 50: 899-908, 2001.

47. Anscher MS, Thrasher B, Rabbani Z, Teicher B and Vujaskovic Z: Antitransforming growth factor antibody $1 \mathrm{D} 11$ ameliorates normal tissue damage caused by high-dose radiation. Int J Radiat Oncol Biol Phys 65: 876-881, 2006.

48. Zheng W, Gao ZH and Wu LN: The clinical study of combination of Chinese and Western medicine in radiation pneumonitis. Chinese Journal of Integrated Traditional and Western Medicine 27: 1121-1127, 2007.

49. Wang JN and Liu L: The effects of Chinese medicine on radiation-induced lung injury. Modern Oncology 10: 1800-1803, 2008. 